\title{
USING INTERNET OF BEHAVIOUR TO INFLUENCE CUSTOMERS - A BUSINESS STRATEGY OR PRIVACY INTRUSION
}

\author{
Ejup Rustemi ${ }^{1 *}$ Mefail Tahiri $^{2}$ \\ ${ }^{1}$ University of Tetova, North Macedonia \\ ${ }^{2}$ University of Tetova, North Macedonia \\ *ejup.rustemi@yahoo.com
}

\begin{abstract}
Data is the thing that drives the world into movement. We as a whole follow up on data; we make evaluation dependent on that; we base our organizations upon that. Hence, legitimate and sound data is essential in all things, from our everyday experience right to how countries communicate and team up between them. Data obtaining and assessment has been diverse all through mankind's set of experiences; various periods had various procedures to examine any given data. The reason for the Internet of Behavior ( $\mathrm{IoB}$ ) is to catch, break down, comprehend and react to a wide range of human practices in a manner that permits following and deciphering those practices of individuals utilizing arising mechanical advancements and improvements in AI calculations. Individuals' practices are observed and motivating forces or disincentives are applied to impact them to perform towards an ideal arrangement of operational boundaries within an organization. What is truly applicable about IoB is that it's difficult to clearly breaking down the way we conduct with it, or how to distinguish which mental factors to impact so we can achieve a specific result. Our paper will deal with the importance that this technology has on our everyday lives and the possible ethical aspects that may be present when using or being part in the chain of such technology.
\end{abstract}

Keywords: manipulation, behavior, information, user.

- $\quad$ Natural and mathematical sciences

\section{INTRODUCTION}

We can start with Young who in 1998 built a concise, eight-question evaluation instrument that surveys habitforming Internet utilization thoroughly dependent on the DSM-IV measures for obsessive usage, including indications of distraction, the requirement for utilizing the Internet with expanding measures of time to acquire similar degrees of fulfillment, ineffective endeavors to decrease unreasonable Internet use, fractiousness when chopping down the action, utilizing the Internet longer than expected, taking a chance with the upkeep of workas well as school-related execution and social connections, lying about the time spent on the Internet, and utilizing the Internet as an adapting methodology to escape from genuine issues. Young (1998) suggested that five out of eight models ought to be met to consider an individual being dependent on the Internet. Nonetheless, scientists contended that Internet use has become a fundamental piece of our lives, bringing about that a few parts of hazardous use (e.g., delayed utilization of the Internet) may not be related with diminished degrees of prosperity (Demetrovics and Király, 2016; Yellowlees and Marks, 2007). All this obssesion is analyzed and evaluated by companies in order to acquire information regarding what makes customers buy a certain product, thus controlling their behavior to their profit.

\section{KNOWING HOW TO BEHAVE}

Today, going past being well known among young people, online media has now advanced into a much-discussed public concern in light of exorbitant or maladaptive use. Indeed, a developing assortment of the writing shows a reliably certain connection between youths' Internet utilization and Internet hazards, but also, profit-driven conduct when buying various products.

Web "enslavement" has been described as the utilization of the Internet to escape from negative sentiments, proceeded with utilization of the Internet regardless of the craving to stop, insight of horrendous feelings when Internet use is incomprehensible, pondering the Internet continually, and the experience personal struggles because of Internet use (Young, 1998). Occasionally we must adopt the satisfactions system to set up the sociomental beginnings of necessities in web-based media use among young people. This gives the premise to analyze how these satisfactions are identified with various examples of web-based media use, bringing about potential outcomes like Internet enslavement and weakness to Internet hazards. One may conceptualize the investigation with Internet enslavement indications as the results of personal satisfactions. 
Regardless of that, Internet habit, a lot of times, is essentially a type of hazard, treating Internet fixation manifestations as indicators may assist with distinguishing side effects that parents and educators need to make prudent moves before it turns into a hazardous obsession. Nevertheless, business companies, use this to their own gain, to sell products and control the way we behave on the Internet.

The utilizations and satisfactions approach expects that social and mental inspirations may make individuals go to media for friendship and different delights. In this regard, the crowd is regularly endeavoring to fulfill certain social and mental necessities like reconnaissance, data chasing, amusement, individual character, or friendship (Dimmick, Sikand, \& Patterson, 1994; Rubin, 1983). The utilizations and satisfactions approach expects that social and mental inspirations may make individuals go to media for friendship and different delights. In this regard, users are regularly endeavoring to fulfill certain social and mental necessities like the ones we just mentioned (Blumler, 1979; Katz, Blumler, \& Gurevitch, 1974). This utilitarian perspective on media use can be a driving force for individuals' thought processes related with the utilization of web-based media (such as IM, blogs, Facebook, and online games).

\section{Fig. 1 Forecast and Foresight of Market Value ${ }^{1}$}

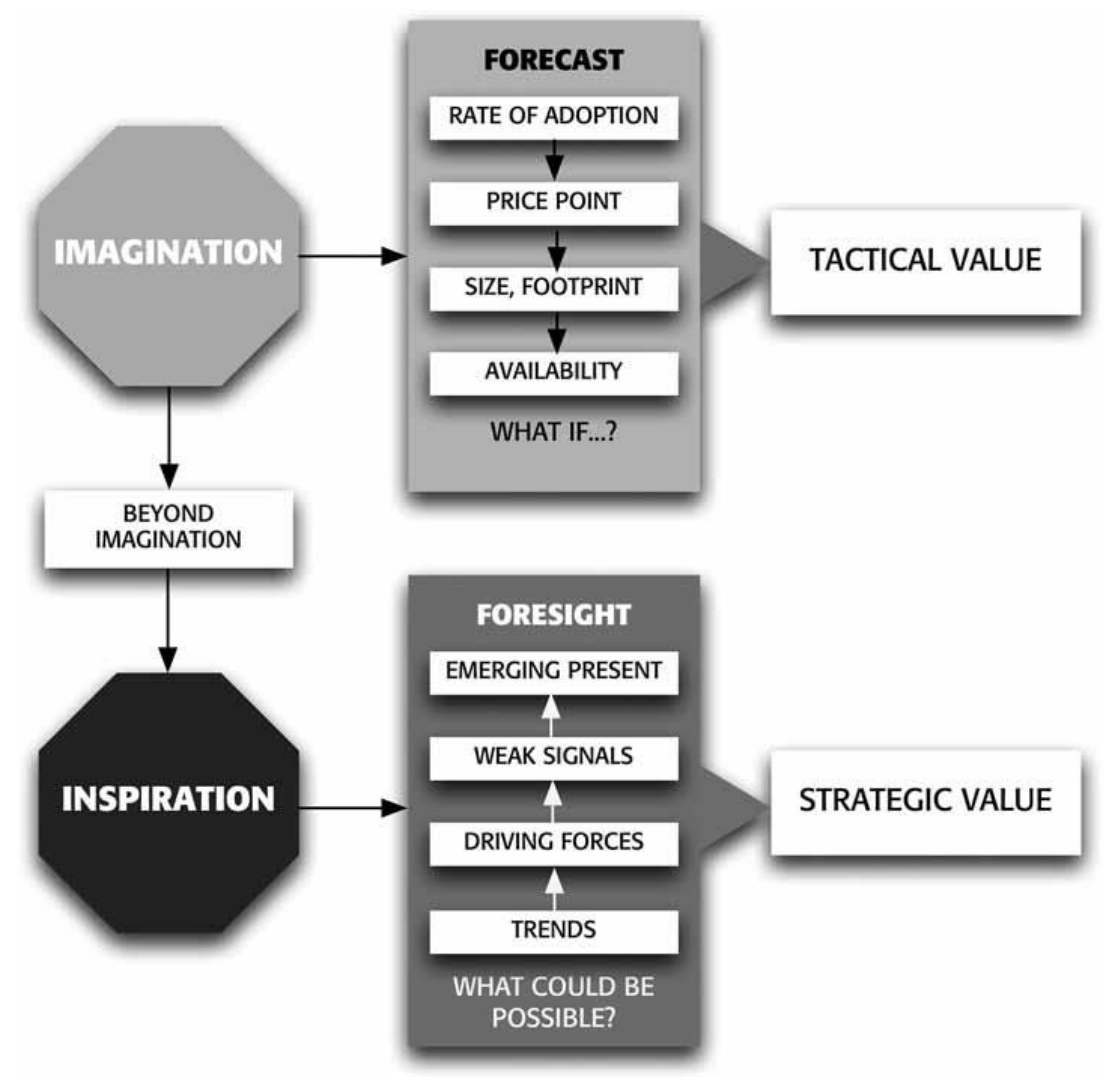

\section{CONTROL OR USER SERVICE?}

Internet of Things (IoT) includes a pervasive presence of sensors, actuators, and other devices that are deployed across large areas and connected via protocols (e.g., Bluetooth, WIFI, LoRA, 5G) that cooperate to meet common objectives. The prevailing trait of IoT is the actual cooperation of the "things" with their surroundings, which empowers novel applications and sets new set of requests. A significant number of these applications are generally dispersed, some have rigid ongoing prerequisites, and in all cases, it is important to keep up with reliable correspondence and versatility to dynamic conditions.

\footnotetext{
${ }^{1}$ Manu, A. (2015)
} 
IoT can, possibly, fundamentally change and further develop city administrations, transportation, agribusiness, medical care, energy creation and circulation, and water protection, among numerous other crucial parts of human existence.

For example, in a research with birds Reynolds (1987) characterizes rushing as the conduct that arises when birds independently apply three neighborhood rules. The main principle looks for coordinating with the speed of adjoining birds (arrangement), the subsequent standard forestalls crashes with different birds or outer items by endorsing a base "bubble" around each bird (division), and the third guideline forces a most extreme distance between neighbors (union). While none of these principles unequivocally characterizes an aggregate conduct, a herd, all things considered, arises because of every individual bird flying as per its given guidelines. In this way, devices can be connected and made to be relatable to one-another with the purpose of mutual communication

Across a scope of practices, there is a developing group of exploration researching the particular and point by point techniques individuals can use to change conduct. One methodology includes the distinguishing proof of Behavior Change Techniques (BCT). Scientific classifications of these intercession procedures have been accounted for general conduct change just as liquor, smoking, and betting (Rodda et al., 2017). Another approach is to identify behavior change strategies (BCS) that individuals use with or without proficient oversight. This information can be analyzed for the presence of progress procedures. For example, a new report including gamblers analyzed two distributed gatherings and through investigation of 2937 posts distinguished 27 discrete changes of behavior (Rodda et al., 2018). Rodda et al. (2018) suggest that change systems were unpredictable (i.e., they incorporate an assortment of activities inside every strategy) and confusion explicit (i.e., the distinguished activities for restricting or diminishing were habitually betting explicit, like restricting admittance to assets for betting). There seems to be an impression of some entanglement between mediation educated scientific categorizations and those dependent on buyer experience (e.g., both incorporate classes related with social help). Notwithstanding, there can be a scientific categorization center with respect to how the change technique could be conveyed though customer educated change system. All these approaches from every day life can be used by corporations to control customer behavior.

\section{BEYOND THE LIMITS}

There are a couple of models - analogies_we may while attempting to comprehend the capability of the environment of everything associated with how we behave on the Internet. Take a tree for instance: the leaves are associated with the branches, the branches associated with the trunk, the trunk is associated with the roots, and the roots with the ground. The human passing by is associated through the feeling of smell and contact; the bloom close by is associated through the ground and the air, and the honey bee that just contacted its petals.

These are largely natural associations, where contact is made. In a natural association, everything offers some benefit to all the other things. The honey bee offers some incentive to the blossom, the bloom offers some benefit to the tree, and the tree offers some incentive to the human.

The generative inquiry in the 'everything associated' nature is: If each individual, article and spot could impart to each other, what might be the topic of their discussions? Corporations use the same strategy to influence how their customers behave when they use the Internet.

To respond to this inquiry, we need to know:

- How would we be able to increase the value of one another?

-What would individuals like to know in certain places?

- How can we increase the value of an item?

- What would customers like to know?

- How can two items increase the value of one another?

-What would customers like to think about certain products?

-What would customers like to think about other customers? 


\section{CONCLUSION}

We should know about what we consider genuine data for the reason that they have an enormous impact on our lives. It can prompt individuals in their home or working environment to behave in a controlled manner. Individuals who surf the web whether for news or for no reason in particular, the likelihood to be given controlled data is incredibly high, therefore a legitimate alert is required. We are altogether inclined to rapidly respond upon some random data, since current life is quick and data assault is at unprecedented levels, and this is the primary issue that we should manage; response should come solely after sufficient affirmation of such data.

The IoB is faced with the affliction of how information is gathered, put away and utilized. Its degree of access is hard to control and in this way all organizations should know about the obligation of IoB use. Google, Facebook or Amazon keep on securing programming that conceivably brings the client from a solitary application to their whole online environment, without their authorization. This presents critical legitimate and security danger to protecting individual rights, which can additionally change our behavior all throughout the planet.

Conduct information can permit cybercriminals to get to delicate information that uncovers client examples, gather and sell property access codes, conveyance courses and in certain events, banking codes. These cybercriminals could take phishing to another level by creating further developed tricks, and accordingly amplifying the probability that clients will be misled.

All in all, businesses should establish proper set of rules to what degree they can intervene in data manipulation which will result in controlled behavior, because if it gets out of control, by trying to increase their profit they may damage their endeavors profoundly.

\section{References}

Blumler, J. (1979). The role of theory in uses and gratifications studies. Communication Research, 6, 9-36.

Demetrovics, Z., Király, O., Koronczai, B., Griffiths, M. D., Nagygyörgy, K., Elekes, Z., Tamás, D., Kun, B., Kökönyei, G., \& Urbán, R. (2016). Psychometric properties of the Problematic Internet Use Questionnaire Short-Form (PIUQ-SF-6) in a nationally representative sample of adolescents. PLoS One, 11(8), e0159409. doi:10.1371/journal.pone.0159409

Dimmick, J., Sikand, J., \& Patterson, S. J. (1994). The gratifications of the household telephone: Sociability, instrumentality and reassurance. Communication Research, 21(5), 643-663.

Katz, E., Blumler, J., \& Gurevitch, M. (1974). Uses and gratifications research. The Public Opinion Quarterly, $36,509-523$.

Manu, A. (2015). Value Creation and the Internet of Things How the Behavior Economy will Shape the 4th Industrial Revolution. Gower, Burlington.

Rodda. S. N., Booth, N., Vacaru, M., Knaebe, B. (2018). Behaviour change strategies for internet, pornography and gaming addiction: A taxonomy and content analysis of professional and consumer websites. Computers in Human Behavior 84 (2018) 467-476

Rubin, A. M. (1983). Television uses and gratifications: The interactions of viewing patterns and motivations. Journal of Broadcasting, 27(1), 37-51.

Young, K. S. (1998). Internet addiction: The emergence of a new clinical disorder. CyberPsychology \& Behavior, 1(3), 237-244. doi:10.1089/cpb.1998.1.237

\section{Bibliography}

Arendt, H. (1964). The Human Condition. Chicago, IL: University of Chicago Press.

Dimmick, J., Kline, S., \& Stafford, L. (2000). The gratification niches of personal e-mail and the telephone competition, displacement and complementarity. Communication Research, 27(2), 227-248.

Esslinger, H. (2012). Design Forward: Creative Strategies for Sustainable Change. Stuttgart: Arnoldsche.

Yellowlees, P. M., \& Marks, S. (2007). Problematic Internet use or Internet addiction? Computers in Human Behavior, 23(3), 1447-1453. doi:10.1016/j.chb.2005.05.004 